\title{
Article \\ Indirect Current Control Method Based on Reference Current Compensation of an LCL-Type Grid-Connected Inverter
}

\author{
Zheng Li ${ }^{1,2, *}$, Linhang Yang ${ }^{2}$, Daliang Yang ${ }^{1,2} \oplus$, Zuwen Peng ${ }^{2}$, Dashuai Shao ${ }^{2} \mathbb{D}$ and Jinbao Liu ${ }^{2}$ \\ 1 Guangxi Key Laboratory of Power System Optimization and Energy Technology, Guangxi University, \\ Nanning 530004, China; yangdl@gxu.edu.cn \\ 2 College of Electrical Engineering, Guangxi University, Nanning 530004, China; lzlkngu@163.com (L.Y.); \\ 1912391054@st.gxu.edu.cn (Z.P.); 1912391056@st.gxu.edu.cn (D.S.); 1912301035@st.gxu.edu.cn (J.L.) \\ * Correspondence: 1912301033@st.gxu.edu.cn
}

check for updates

Citation: Li, Z.; Yang, L.; Yang, D.; Peng, Z.; Shao, D.; Liu, J. Indirect Current Control Method Based on Reference Current Compensation of an LCL-Type Grid-Connected Inverter. Energies 2022, 15, 965. https://doi.org/10.3390/en15030965

Academic Editor: Sérgio Cruz

Received: 29 December 2021

Accepted: 25 January 2022

Published: 28 January 2022

Publisher's Note: MDPI stays neutral with regard to jurisdictional claims in published maps and institutional affiliations.

Copyright: (C) 2022 by the authors. Licensee MDPI, Basel, Switzerland. This article is an open access article distributed under the terms and conditions of the Creative Commons Attribution (CC BY) license (https:// creativecommons.org/licenses/by/ $4.0 /)$.

\begin{abstract}
NPC (neutral point clamped converter) is widely used in medium- and high-voltage grid connection because of its small power devices, simple overall structure, and easy control. This paper presents an improved indirect current control strategy for an LCL-type NPC. Firstly, the reference current is compensated to suppress the resonant peak of the LCL filter and improve the tracking accuracy of the output current. Then, with the relationship between state variables, the control structure is optimized by introducing the non-PLL control method, so that the sensors are reduced to only two sets. Finally, the traditional differential operator is improved to compensate the calculation delay in digital control. The experimental results show that the amplitude of thee grid-connected current is consistent with the reference value, the phase deviation is reduced from $7^{\circ}$ to about $1^{\circ}$, and the transient response time is shortened to $1 / 3$ of that of the traditional method.
\end{abstract}

Keywords: LCL filter; three-phase grid-connected inverter; indirect current control; reference current compensation; calculation delay

\section{Introduction}

With the social demand for energy increasing, the energy crisis is becoming increasingly prominent. Meanwhile, people's awareness of environmental protection is increasing, and distributed generation based on new energy is increasing in power systems. The grid-connected inverter, as the interface that connects to the power grid, has a huge demand [1,2]. To achieve the technical requirements of grid-connected inverters (e.g., the harmonic content in the grid-connected current cannot be more than $5 \%$ ), it is necessary to install filters on the grid-connected side of the inverter, usually with L-type, LC-type, LCL-type, or other more complex structures. The LCL-type filter has been applied increasingly more in grid-connected inverters due to its advantages of a small volume, strong attenuation of high-frequency harmonics, higher quality of grid-connected current control, etc. However, the resonance in the LCL filter may lead to system instability [3-5]. At present, studies on LCL-type grid-connected inverters have mainly focused on the stability problems caused by LCL resonant peak [6-8] and digital control delay $[9,10]$.

Scholars have carried out extensive studies on the resonance problem of LCL filters, and usually, solutions include passive damping and active damping strategies [6]. Passive damping is realized through series and parallel damping resistors, which is simple to implement, but the system loss is increased and the high-frequency filtering ability of the filter is reduced [7]. Active damping suppresses resonance by changing the control structure. Currently, active damping strategies mainly include feedback control based on an additional digital filter [11-13], feedback control based on model reduction [14,15], and feedback control based on additional variables [16-20].

Among the above active damping methods, capacitive current feedback based on additional variables has attracted much attention due to its simplicity $[8,16]$. LCL-type 
inverter capacitive current feedback usually has two current control methods. One is direct current control using the grid-connected current for closed-loop control [21,22]. The second is indirect current control with closed-loop control of the inverter-side output current [12,23]. Most active damping strategies adopt direct current control. In [8], an optimal design scheme for the capacitive current feedback coefficient was proposed to enhance the stability of the converter system at a resonant frequency. In [22], an external current loop scheme with proportional resonance plus odd harmonic repetition control was designed to realize high-precision tracking of the grid-connected current. Although these direct current control strategies can ensure the stability of the grid-connected current and high-precision tracking, they cannot directly detect overcurrent at the switch tube on the inverter side, and there are potential safety hazards regarding damage to the switch tube due to overcurrent overheating [24]. Therefore, some products adopt an indirect current control mode to ensure the safety of the grid-connected inverter. The filter capacitor branch is equivalent to an open circuit, and the fundamental current is ignored while the indirect current mode is equivalent to the direct current mode. However, when the grid-connected current contains high-frequency current components, the effect of the inductance and capacitor on the inverter side will result in relatively obviously deviation [25,26]. In other words, since the control target of indirect current control is the intermediate output of the system, the tracking accuracy of the grid-connected current will be reduced. At the same time, when high-frequency current resonates between the capacitors, bad oscillation in the gate current may result in unstable output of the stable intermediate variable [27]. In addition, the existing control of the grid-connected inverter is based on a phase-locked loop, and the control parameters of the phase-locked loop also affect the control accuracy and stability of indirect current control [28]. Therefore, how to adopt a more effective strategy for indirect current control based on capacitive current feedback is still worthy of further study.

The stability caused by digital control delay is another problem in the application of LCL-type inverters. The difference method based on the sampling time is often adopted in traditional digital realization of differential operators, which leads to calculation delay of about one beat between the calculated value and the actual signal [29]. Control delay will introduce phase lag, which limits the bandwidth of the control loop and may cause instability in the system $[10,30]$. Therefore, to improve the stability and control performance of grid-connected inverters, it is necessary to reduce the control delay. The authors of [9] proposed the instantaneous sampling method for capacitive current. If the sampling time is moved to the loading time of the modulation signal, the corresponding calculation delay will be less than one beat to reduce the calculation delay. The authors of [10] proposed the real-time operation method of the dual sampling mode of capacitive current, which selects the single-stage frequency doubling modulation mode as being equivalent to updating the modulation wave immediately after the completion of sampling of the capacitive current signal, which can completely eliminate the calculation delay. However, the existing methods need to change the sampling mode, which is more complicated in DSP implementation and increases the amount of code calculation.

Aiming to resolve the stability problems caused by LCL resonance and the deviation between the amplitude and phase of the grid-connected current caused by indirect current control and digital delay, the following work was done in this paper:

(1) An indirect current control method based on reference current compensation is proposed to achieve high-precision control of grid-connected current and suppress the resonance in the LCL-type filter. At the same time, a PLL-free control strategy is introduced to optimize the control structure using the relationship between system state variables, to reduce the number of sensors and the system cost.

(2) This paper compensates for the calculation delay of 0.5 beat by multiplying the leading operator $z^{0.5}$ based on the traditional backward difference operator [29], and this method only compensates the calculation delay in digital control by changing the control structure of the system. 
(3) The effectiveness of the proposed control strategy is verified by the digital simulation and experimental results of the three-phase LCL-type inverter.

The outline of this paper is structured as follows: The traditional indirect current control strategy is described briefly in Section 2. Section 3 introduces the improved control method and compares it with the traditional method through a Bode diagram. Simulation and experiments verify the feasibility of the proposed method in Section 4 and Section 5. Section 6 summarizes the conclusions derived from this study.

\section{Traditional Indirect Current Control for the LCL Grid-Connected Inverter}

Figure 1 shows the main circuit of the three-phase LCL-type inverter, in which the inverter bridge adopts a neutral point clamped converter (NPC) [31]. In Figure 1, each phase arm has 4 IGBTs and 2 clamp diodes, respectively. $C_{\mathrm{dc} 1}$ and $C_{\mathrm{dc} 2}$ are the DC side splitting capacitors, where point $\mathrm{N}$ is connected with the midpoint of the clamping diode, so that the voltage at both ends of each IGBT is half of the total voltage $U_{\mathrm{dc}}$ of the DC side when it is turned off. $L_{1}$ is the inverter-side inductance, $C_{\mathrm{f}}$ is the filter capacitor, $L_{2}$ is the grid-side inductance, $L_{\mathrm{g}}$ is the grid impedance, $u_{\mathrm{g}}$ is the grid voltage, $u_{x}(x=\mathrm{a}, \mathrm{b}, \mathrm{c})$ is the three-phase AC voltage output by the arm, $u_{\mathrm{cf}}$ is the capacitor voltage of the LCL filter, $i_{\mathrm{cf}}$ is the capacitor current of the LCL filter, $i_{1}$ is the inverter-side inductance current, and $i_{2}$ is the grid-connected current.

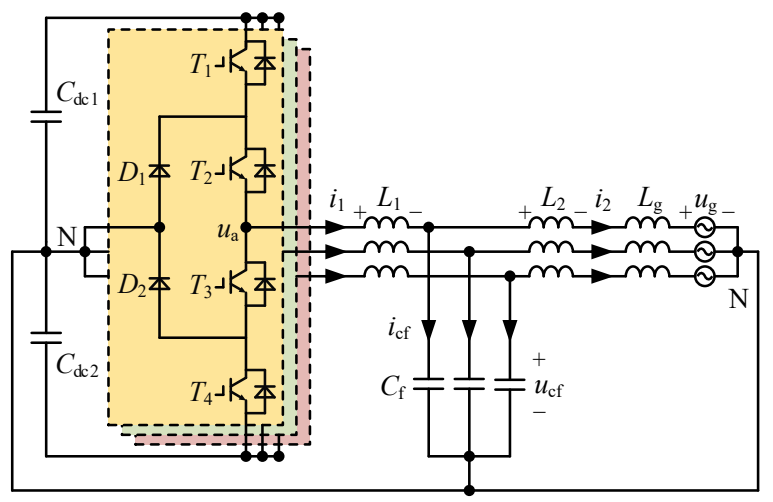

Figure 1. Main circuit of the three-phase LCL-type grid-connected inverter.

Assuming that the grid voltage, switching tube, and filtering components are in an ideal state, and the grid impedance $L_{g}=0$, the state equation of the 3-phase LCL-type grid-connected inverter can be identified according to Kirchhoff's voltage and current law, as shown in Equations (1)-(3). It is easy to know that it is a third-order control system, and the stability of the grid-connected inverter is affected to some extent because of the resonant peak in the frequency response of LCL:

$$
\begin{aligned}
& L_{1} \frac{d i_{1}}{d t}=u_{x}-u_{\mathrm{cf}} \\
& L_{2} \frac{d i_{2}}{d t}=u_{\mathrm{cf}}-u_{\mathrm{g}} \\
& C_{\mathrm{f}} \frac{d u_{\mathrm{cf}}}{d t}=i_{1}-i_{2}
\end{aligned}
$$

Therefore, the active damping strategy of the capacitive current feedback is usually adopted [8]. Taking phase A as an example, the traditional indirect current control block diagram of an LCL-type grid-connected inverter is shown in Figure 2. 


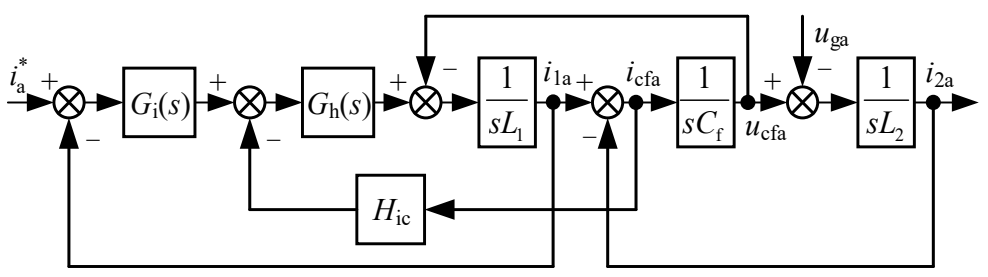

Figure 2. Conventional indirect current control block of the LCL-type grid-connected inverter.

In Figure 2, $i_{\mathrm{a}}^{*}$ is the reference current, $G_{\mathrm{i}}(s)$ is the qPR current controller, $H_{\mathrm{ic}}$ is the capacitance current feedback coefficient, and $Z_{\mathrm{L} 1}=s L 1, Z_{\mathrm{L} 2}=s L_{2}, Z_{\mathrm{C}}=1 / s C_{\mathrm{f}}$ are the impedance forms of the inverter-side inductance, grid-side inductance, and filter capacitor, respectively. $G_{h}(s)$ is the equivalent transfer function of the PWM modulated wave to the output voltage of the inverter in digital control [5]:

$$
G_{\mathrm{h}}(s)=e^{-1.5 s T_{s}} K_{\mathrm{PWM}}
$$

Equation (4) includes the one-beat control delay $T_{\mathrm{s}}$ generated by thee sampling calculation, the half-beat control delay $0.5 T_{\mathrm{s}}$ generated by the zero-order hold during loading, and the equivalent gain $K_{\mathrm{PWM}}=U_{\mathrm{dc}} / U_{\text {tri }}$ of NPC, where $U_{\text {tri }}$ is the amplitude of the triangular carrier.

According to the above analysis, in the traditional indirect current control of the LCL-type grid-connected inverter, the closed-loop control indirect object is the inductance current on the inverter side while the grid-connected current as the control direct target is not directly controlled. As a result, the amplitude and phase of the output steady-state grid-connected current deviate from the expected value, which leads to deterioration of the current tracking control.

\section{Improved Indirect Current Control Strategy}

In order to overcome the defects of the traditional method mentioned above, an indirect current control method based on the reference current compensation is proposed in this paper, which can ensure high-precision control and calibration of the phase of the output grid-connected current of the system and realize the grid-connected unit power factor. On this basis, a PLL-free control method is adopted to obtain the preliminary reference current signal before compensation, which avoids phase detection by using the PLL in the traditional $d q$ coordinate system, which not only simplifies the control structure, but also reduces the operation time of the system and improves the response speed of the system.

\subsection{Reference Current Compensation Control Strategy}

In a three-phase $\mathrm{AC}$ system, independent control of the active and reactive components of the current can be realized, respectively, by converting the instantaneous voltage into the corresponding instantaneous active and reactive components.

It is assumed that $e_{\mathrm{a}}, e_{\mathrm{b}}$, and $e_{\mathrm{c}}$ are the instantaneous active voltage components of the three-phase balanced power grid, and after Clark transformation, they are transformed into the active voltage vector $\boldsymbol{e}_{\mathrm{s}}=\left(\boldsymbol{e}_{\alpha} \boldsymbol{e}_{\beta}\right)^{\mathrm{T}}$ in the $\alpha \beta$ coordinate system. The reactive voltage vector in the $\alpha \beta$ coordinate system is defined as $\boldsymbol{e}_{\mathrm{s}}^{\prime}=\left(\boldsymbol{e}_{\alpha}^{\prime} \boldsymbol{e}_{\beta}^{\prime}\right)^{\mathrm{T}}$, which is $90^{\circ}$ ahead of the active voltage vector. Then, the magnitude of the combined voltage in the $\alpha \beta$ coordinate system is shown in Equation (5):

$$
\left|e_{\mathrm{s}}\right|=\left|e_{\mathrm{s}}^{\prime}\right|=\sqrt{e_{\alpha}^{2}+e_{\beta}^{2}}
$$

The unit vector calculation (UVC) of the active and reactive voltage vectors is respectively expressed as:

$$
\left[\begin{array}{c}
\boldsymbol{v}_{\alpha} \\
\boldsymbol{v}_{\beta}
\end{array}\right]=\frac{1}{\left|\boldsymbol{e}_{\mathrm{s}}\right|}\left[\begin{array}{l}
\boldsymbol{e}_{\alpha} \\
\boldsymbol{e}_{\beta}
\end{array}\right]=\left[\begin{array}{c}
\cos \omega t \\
\sin \omega t
\end{array}\right]
$$




$$
\left[\begin{array}{c}
v_{\alpha}^{\prime} \\
\boldsymbol{v}_{\beta}^{\prime}
\end{array}\right]=\frac{1}{\left|\boldsymbol{e}_{\mathrm{s}}\right|}\left[\begin{array}{c}
\boldsymbol{e}_{\alpha}^{\prime} \\
\boldsymbol{e}_{\beta}^{\prime}
\end{array}\right]=\left[\begin{array}{c}
-\boldsymbol{v}_{\beta} \\
\boldsymbol{v}_{\alpha}
\end{array}\right]=\left[\begin{array}{c}
-\sin \omega t \\
\cos \omega t
\end{array}\right]
$$

In Equations (6) and (7), $\omega$ refers to the angular frequency of the grid voltage.

According to the instantaneous power theory, the expressions of the instantaneous active power $p$ and reactive power $q$ in the $\alpha \beta$ coordinate system are shown in Equation (8):

$$
\left[\begin{array}{l}
p \\
q
\end{array}\right]=\left[\begin{array}{ll}
\boldsymbol{e}_{\alpha} & \boldsymbol{e}_{\beta} \\
\boldsymbol{e}_{\alpha}^{\prime} & \boldsymbol{e}_{\beta}^{\prime}
\end{array}\right]\left[\begin{array}{l}
i_{\alpha} \\
i_{\beta}
\end{array}\right]
$$

According to Equations (5)-(8), the preliminary reference current calculation (PRCC) in the $\alpha \beta$ coordinate system is shown in Equation (9):

$$
\left[\begin{array}{c}
i_{\alpha}^{*} \\
i_{\beta}^{*}
\end{array}\right]=\frac{1}{\left|e_{\mathrm{s}}\right|}\left[\begin{array}{cc}
v_{\alpha} & \boldsymbol{v}_{\alpha}^{\prime} \\
v_{\beta} & v_{\beta}^{\prime}
\end{array}\right]\left[\begin{array}{l}
p \\
q
\end{array}\right]=\left[\begin{array}{cc}
\cos \omega t & -\sin \omega t \\
\sin \omega t & \cos \omega t
\end{array}\right]\left[\begin{array}{l}
i_{\mathrm{d}}^{*} \\
i_{\mathrm{q}}^{*}
\end{array}\right]
$$

In Equation (9), $i_{\mathrm{d}}^{*}$ and $i_{\mathrm{q}}^{*}$ are the reference values of the active current and the reactive current, respectively. Using Clark transformation, the 3-phase preliminary reference current shown in Equation (10) in the abc coordinate system can be obtained:

$$
\left[\begin{array}{c}
i_{\mathrm{a}}^{*} \\
i_{\mathrm{b}}^{*} \\
i_{\mathrm{c}}^{*}
\end{array}\right]=\left[\begin{array}{c}
I^{*} \cos (\omega t+\varphi) \\
I^{*} \cos \left(\omega t+\varphi-120^{\circ}\right) \\
I^{*} \cos \left(\omega t+\varphi+120^{\circ}\right)
\end{array}\right]
$$

In addition, considering that the inductance value $L_{2}$ is usually very small, compared with the grid voltage $u_{\mathrm{g}}$, the voltage $u_{\mathrm{L} 2}$ can be ignored [4]. At this point, the three-phase capacitor voltage $u_{\mathrm{cf}}$ is approximately equal to the three-phase grid voltage $u_{\mathrm{g}}$. Therefore, the angular frequency of $u_{\mathrm{cf}}$ can be obtained from Equations (5)-(7) without using the traditional phase-locked loop. Accordingly, the three-phase preliminary reference current is shown in Equation (11):

$$
\left[\begin{array}{c}
i_{\mathrm{a}}^{*} \\
i_{\mathrm{b}}^{*} \\
i_{\mathrm{c}}^{*}
\end{array}\right]=\left[\begin{array}{c}
I^{*} \cos \left(\omega^{\prime} t+\varphi^{\prime}\right) \\
I^{*} \cos \left(\omega^{\prime} t+\varphi^{\prime}-120^{\circ}\right) \\
I^{*} \cos \left(\omega^{\prime} t+\varphi^{\prime}+120^{\circ}\right)
\end{array}\right]
$$

In Equations (10) and (11), $I^{*}$ is the amplitude of the preliminary reference current, which is equal to the amplitude of the given $i_{\mathrm{d}}^{*}$ and $i_{\mathrm{q}}^{*}$ in the $d q$ coordinates system. $\varphi$ and $\varphi^{\prime}$ are the initial phase angles of the three-phase preliminary reference current in the abc coordinates system.

Figure 3 presents the indirect current control block diagram of the reference current compensation proposed in this paper. Taking phase A as an example, the preliminary reference current $i_{\mathrm{a}}^{*}$ is compared with the sampling value of the grid-connected current $i_{2 \mathrm{a}}$ to obtain the error $\varepsilon_{\text {rca }}$, which is then adjusted using the qPR controller to output the required reference current compensation $i_{\text {rca }}^{*}$. The compensation value is directly superimposed on the reference current loop, and the new value of the A-phase reference current after compensation is shown in Equation (12):

$$
i_{\mathrm{rna}}^{*}=i_{\mathrm{a}}^{*}+i_{\mathrm{rca}}^{*}
$$




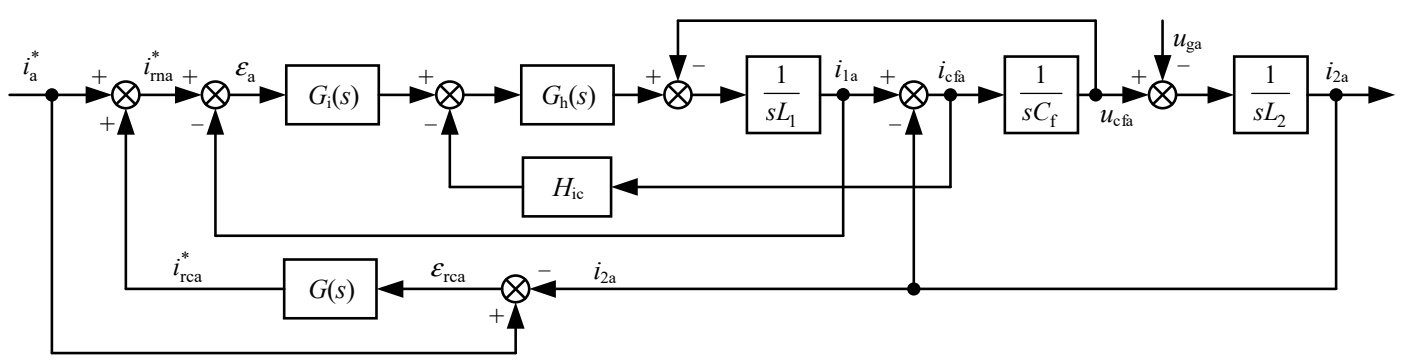

Figure 3. Control block diagram of indirect current control with reference current compensation.

However, it can be seen from the control block diagram in Figure 3 that each phase required additional sensors to detect the grid-connected current $i_{2}$. Further, Figure 3 can be optimized to produce Figure 4 by combining it with Equations (13) and (14). At this point, the grid-connected current inner loop control only needs to collect two sets of sensors of the inductance current $i_{1 x}(x=\mathrm{a}, \mathrm{b}, \mathrm{c})$ and filter capacitor voltage $u_{\mathrm{cf} x}(x=\mathrm{a}, \mathrm{b}, \mathrm{c})$ on the three-phase inverter side, to achieve the same control effect and reduce the costs associated with the system hardware:

$$
\begin{aligned}
& i_{\mathrm{cf}}={ }_{s} C_{\mathrm{f}} u_{\mathrm{cf}} \\
& i_{1}=i_{2}+i_{\mathrm{cf}}
\end{aligned}
$$

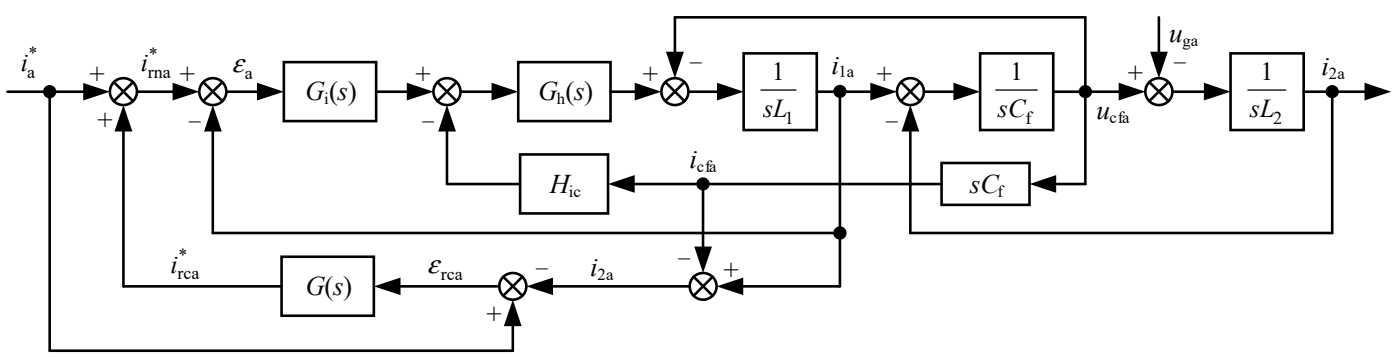

Figure 4. Control block diagram of optimized indirect current control with reference current compensation.

MATLAB was used to produce a contrast diagram of the amplitude-frequency characteristic curve from Figures 2 and 4, as shown in Figure 5. It can be seen from Figure 5 that the loop gain at the fundamental wave of the system increases after the reference current compensation $i_{\text {rca }}^{*}$ is introduced. This indicates that the proposed control structure can track the instruction value better and the grid-connected current steady-state error is reduced.

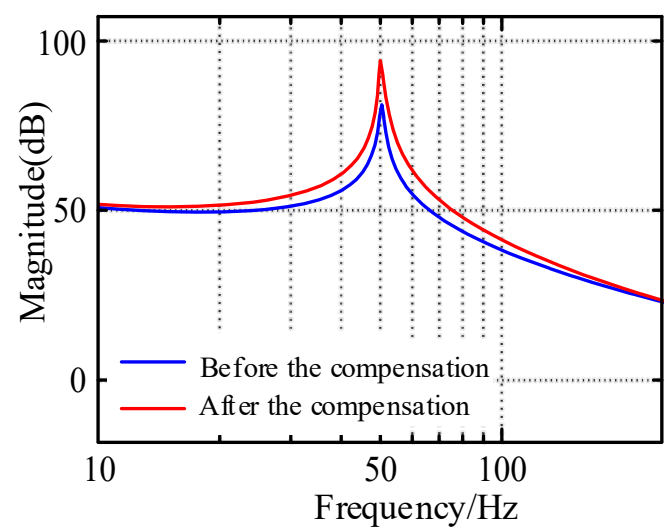

Figure 5. Comparison of the amplitude-frequency characteristic diagram. 


\subsection{Computational Delay Compensation for Discrete Digital Control}

In order to realize the control block diagram shown in Figure 4, the differential operator $s$ is usually implemented using the backward difference method [29], as shown in Equations (15) and (16):

$$
\begin{gathered}
i_{\mathrm{cf}}=\left.{ }_{s} C_{\mathrm{f}} u_{\mathrm{cf}}\right|_{s=\frac{z-1}{z T_{\mathrm{s}}}}=\frac{z-1}{z T_{\mathrm{s}}} C_{\mathrm{f}} u_{\mathrm{cf}} \\
z i_{\mathrm{cf}}=\frac{1}{T_{\mathrm{s}}} C_{\mathrm{f}} u_{\mathrm{cf}}(z-1)
\end{gathered}
$$

If $z=e^{s T_{s}}$, Taylor expansion of an exponential function:

$$
e^{s T_{\mathrm{s}}}=1+s T_{\mathrm{s}}+\frac{1}{2} s^{2} T_{\mathrm{s}}^{2}+\frac{1}{6} s^{3} T_{\mathrm{s}}^{3}+\ldots
$$

The higher-order terms above $s^{2}$ are omitted and substituted into Equation (16):

$$
z i_{\mathrm{cf}}=\frac{e^{s T_{\mathrm{s}}}-1}{T_{\mathrm{s}}} C_{\mathrm{f}} u_{\mathrm{cf}} \approx \frac{s T_{\mathrm{s}}}{T_{\mathrm{s}}} C_{\mathrm{f}} u_{\mathrm{cf}}=s C_{\mathrm{f}} u_{\mathrm{cf}}
$$

It can be seen that the calculation delay of the capacitance current $i_{\mathrm{cf}}$ calculated by $u_{\mathrm{cf}}$ and the actual signal $i_{\text {cf_real }}$ is about one beat. Similarly, if the forward difference rule is adopted, the calculated value is about one beat ahead of the actual signal.

Therefore, on the basis of the traditional backward difference operator, this paper compensates for the calculation delay of 0.5 beat by the leading operator $z^{0.5}$, so Equation (15) can be written as:

$$
i_{\mathrm{cf}}=z^{0.5} \frac{(z-1)}{z T_{\mathrm{s}}} C_{\mathrm{f}} u_{\mathrm{cf}}
$$

This compensation is physically difficult to achieve. This paper achieves the compensation by designing an FIR filter [21], assuming Equation (20):

$$
z^{-d}=H(z)=\sum_{n=0}^{N}\left[h(n) z^{-n}\right]
$$

where $n$ is an integer $(0,1,2, \ldots), d$ is the delay beat number, $N$ is the filter order, and $h(n)$ is the FIR filter coefficient:

$$
h(n)=\frac{1}{2 \pi} \int_{-\pi}^{\pi} e^{-j \omega d} e^{j \omega n} d \omega=\frac{\sin [\pi(n-d)]}{\pi(n-d)}
$$

Equation (21) is linearized by the Lagrange linear interpolation method to obtain Equation (22):

$$
h(n)=\prod_{i=0, i \neq n}^{N} \frac{d-i}{n-i}
$$

According to Equations (19)-(22), it can be concluded that the filter capacitive current signal at time $k$ is Equation (23):

$$
i_{\mathrm{cf}}(k)=\frac{C_{\mathrm{f}}}{T_{\mathrm{s}}}\left\{\sum_{n=0}^{N}\left[\left(\prod_{i=0, i \neq n}^{N} \frac{-0.5-i}{n-i}\right) u_{\mathrm{cf}}(k-n)\right]-\sum_{n=0}^{N}\left[\left(\prod_{i=0, i \neq n}^{N} \frac{-0.5-i}{n-i}\right) u_{\mathrm{cf}}(k-n-1)\right]\right\}
$$

Using the filter order $N=2$ in the above equation, Equation (24) can be obtained:

$$
i_{\mathrm{cf}}(k)=\frac{C_{\mathrm{f}}}{8 T_{\mathrm{s}}}\left[15 u_{\mathrm{cf}}(k)-25 u_{\mathrm{cf}}(k-1)+13 u_{\mathrm{cf}}(k-2)-3 u_{\mathrm{cf}}(k-3)\right]
$$


The calculated value of the grid-connected current at moment $k$ is shown in Equation (25):

$$
i_{2}(k)=i_{1}(k)-i_{\mathrm{cf}}(k)
$$

\subsection{System Stability Analysis}

The closed-loop stability of the control system was analyzed with the improved indirect current control strategy. MATLAB was used to construct a bode diagram of the control block diagram shown in Figure 4, as shown in Figure 6. It can be seen from Figure 6 that the amplitude margin $\mathrm{GM}=5.77 \mathrm{~dB}>0$ at the crossing frequency on the amplitudefrequency characteristic curve, and the phase margin $\mathrm{PM}=46.32^{\circ}>0$ at the shear frequency on the phase-frequency characteristic curve, indicating that the control system is stable.

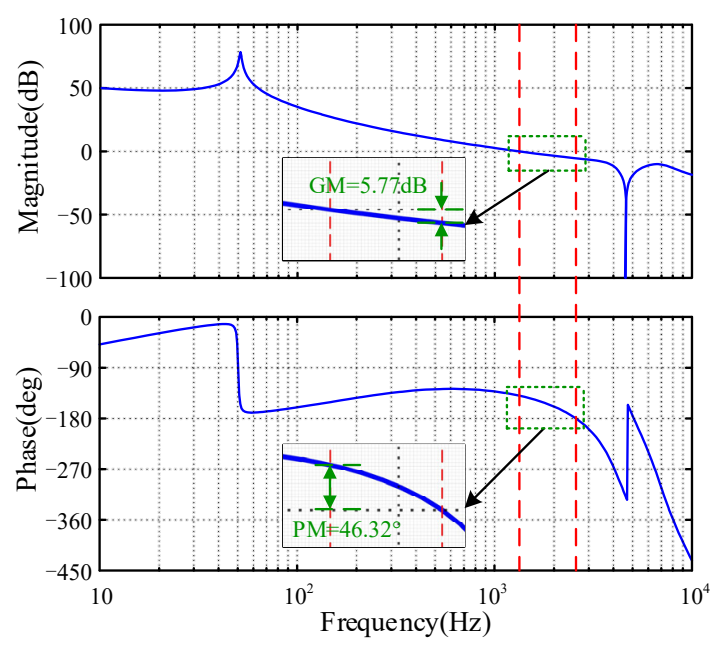

Figure 6. Bode diagram of the improved indirect current control method characteristic diagram.

In addition, to further analyze the adaptability of the proposed method to a weak power grid, Figure 7 shows the closed-loop pole diagram of the control system when the power grid impedance value $L_{\mathrm{g}}$ changes from 0 to $1.54 \mathrm{mH}$ (corresponding to a short-circuit ratio SCR $=10$ [32]). It can be seen from Figure 7 that the poles of the closed-loop control system are all within the unit circle with a certain margin in the $L_{g}$ variation range. This indicates that the grid-connected inverter system can maintain stability. Therefore, the proposed method shows good robustness in a weak power grid.

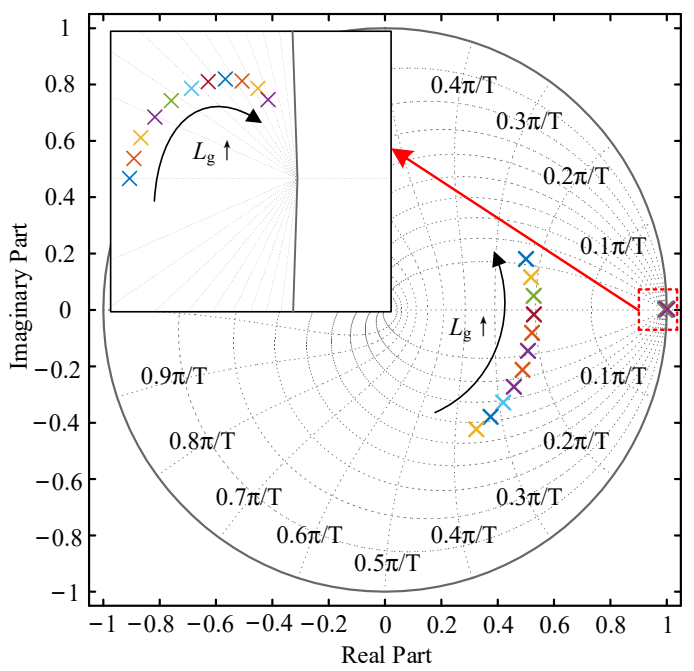

Figure 7. Closed-loop pole diagrams of the system under various grid impedances. 


\section{Digital Simulation Results and Analysis}

To verify the feasibility of the improved method, a discrete domain simulation model of the three-phase LCL-type grid-connected inverter was established in MATLAB/Simulink. The simulation control parameters are shown in Table 1. The corresponding system control block diagram is shown in Figure 8. Its basic structure is a double closed-loop structure comprising a DC voltage outer loop and grid-connected current inner loop. To balance the voltage of the upper and lower split capacitors on the DC side of the NPC inverter and reduce the active power fluctuation caused by midpoint potential imbalance, a voltage equalization control structure on the DC side is also introduced.

Table 1. Parameters used for simulation.

\begin{tabular}{ccc}
\hline Parameters & Symbol & Value \\
\hline DC-side splitting capacitors & $C_{\mathrm{dc} 1}, C_{\mathrm{dc} 2}$ & $4200 \mu \mathrm{F}$ \\
Inverter-side inductance & $L_{1}$ & $600 \mu \mathrm{H}$ \\
filter capacitor & $C_{\mathrm{f}}$ & $20 \mu \mathrm{H}$ \\
Grid-side inductance & $L_{2}$ & $250 \mu \mathrm{H}$ \\
Grid voltage & $u_{\mathrm{gline}}$ & $380 \mathrm{~V}$ \\
DC-side reference voltage & $U_{\mathrm{dc}}$ & $780 \mathrm{~V}$ \\
Frequency of fundamental & $f_{\mathrm{o}}$ & $50 \mathrm{~Hz}$ \\
voltage & $f_{\mathrm{s}}$ & $12.8 \mathrm{kHz}$ \\
Sampling frequency & $K_{\mathrm{pi}}, K_{\mathrm{ri}}$ & 12,520 \\
$G_{\mathrm{i}}(s)$ & $K_{\mathrm{pc}}, K_{\mathrm{rc}}$ & $1.5,250$ \\
$G(s)$ & $H_{\mathrm{ic}}$ & 1 \\
\hline
\end{tabular}

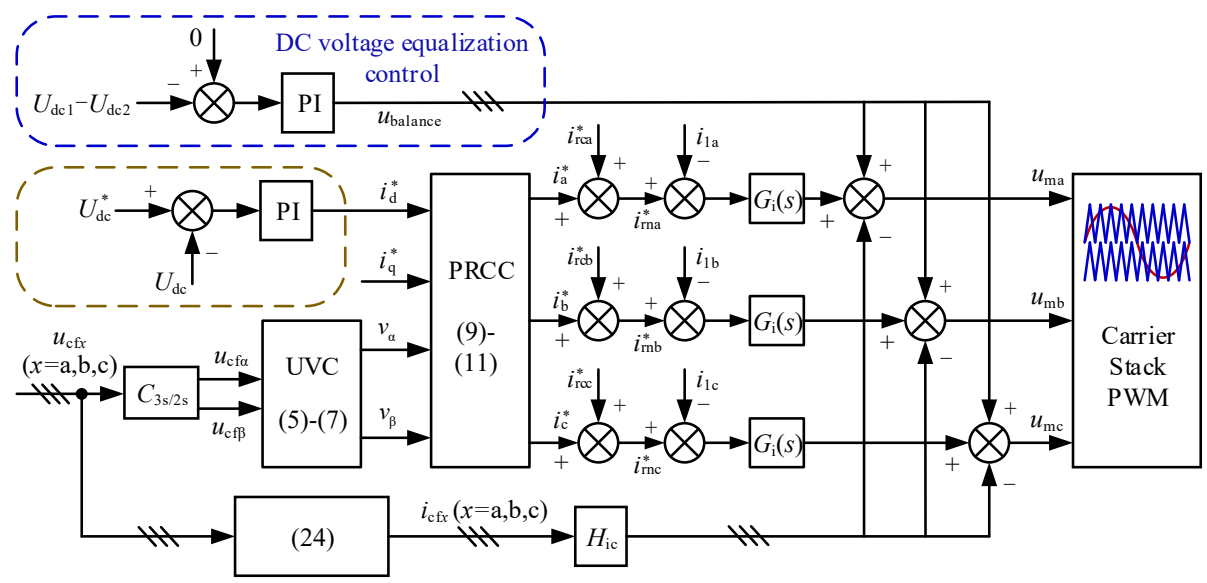

Figure 8. Control block diagram of the three-phase LCL-type grid-connected inverter system.

\subsection{Steady-State Simulation of Grid-Connected Current Control}

In this section, the traditional indirect current control method shown in Figure 2 and the indirect current control method proposed are respectively adopted and an active current with an amplitude of $10 \mathrm{~A}$ is simulated at $0.2 \mathrm{~s}$. Figure 9 shows the simulation waveform of the A-phase grid-connected current, and Figures 10 and 11 show the power factor curve and FFT analysis results of the grid-connected current, respectively. It can be seen from Figures 9-11 that the measured amplitude of $i_{2 \mathrm{a}}$ is $8.75 \mathrm{~A}$, and its THD is $5.3 \%$ when the traditional method is adopted. In addition, the phase difference between $u_{\mathrm{ga}}$ and $i_{\mathrm{a}}$ is about $10^{\circ}$, and the corresponding power factor is about 0.984 . The results show that the steady-state value of the grid-connected current shows deviation in its amplitude and phase, reduces the power factor of the system, and the current quality is poor. When using the method in this paper, the output grid-connected current is almost in phase with the grid voltage. It can be seen from Figure 10 that the system operates almost as the unit power factor. According to Figure 11b, the measured amplitude of $i_{2 \mathrm{a}}$ is $10.01 \mathrm{~A}$, and its THD is 
$2.08 \%$. The results show that the amplitude and phase deviations of the output current are almost eliminated, and the high-precision output and unit power factor operation are realized using the proposed method.

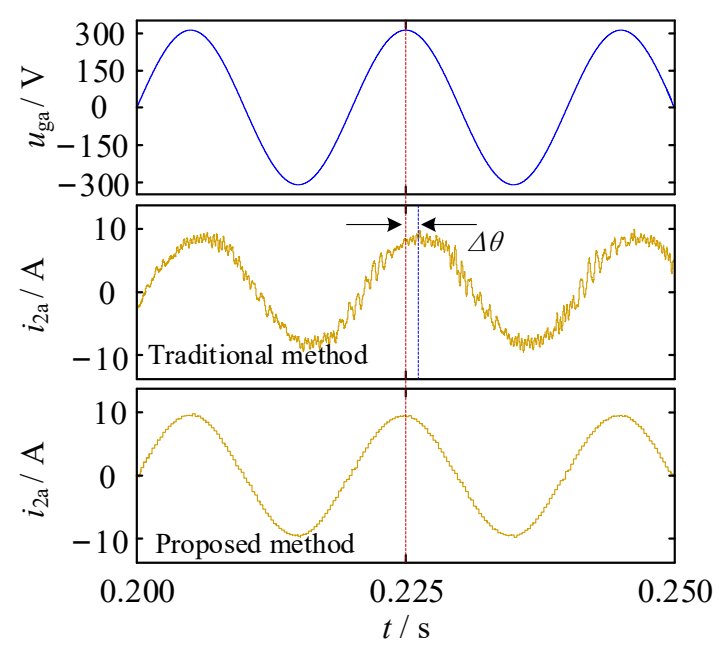

Figure 9. Simulation results of the grid current.

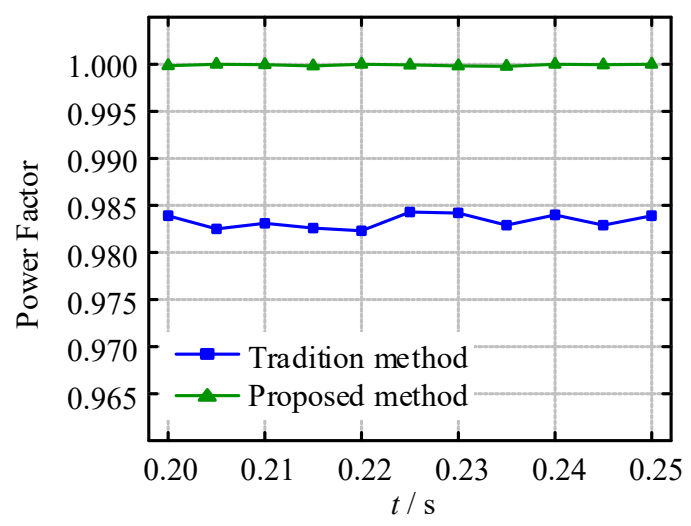

Figure 10. Simulation results of the power factor.

Fundamental $(50 \mathrm{~Hz})=8.75$,

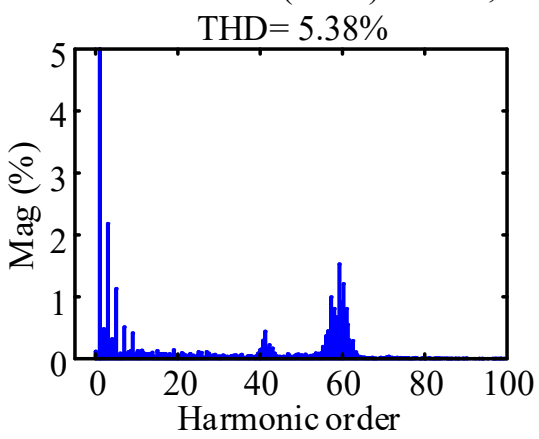

(a)
Fundamental $(50 \mathrm{~Hz})=10.01$,

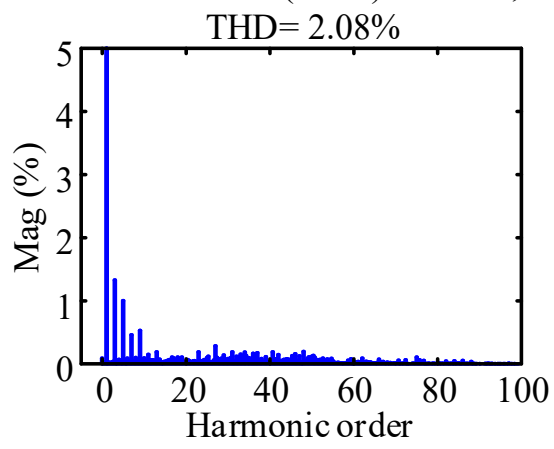

(b)

Figure 11. FFT analysis of the grid current: (a) Traditional method; (b) proposed method.

\subsection{Simulation Comparison of the Dynamic Response}

To verify that the control strategy in this paper has a better dynamic performance, the amplitude of the reactive current instruction $i_{\mathrm{q}}^{*}$ of the inverter was set to change from 0 to $10 \mathrm{~A}$ when the simulation ran for $0.2 \mathrm{~s}$ under no-load conditions. A comparison of the simulation results is shown in Figure 12. 


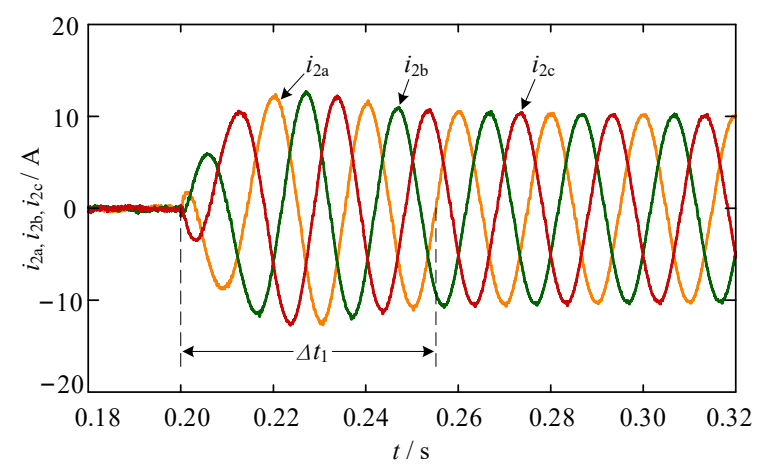

(a)

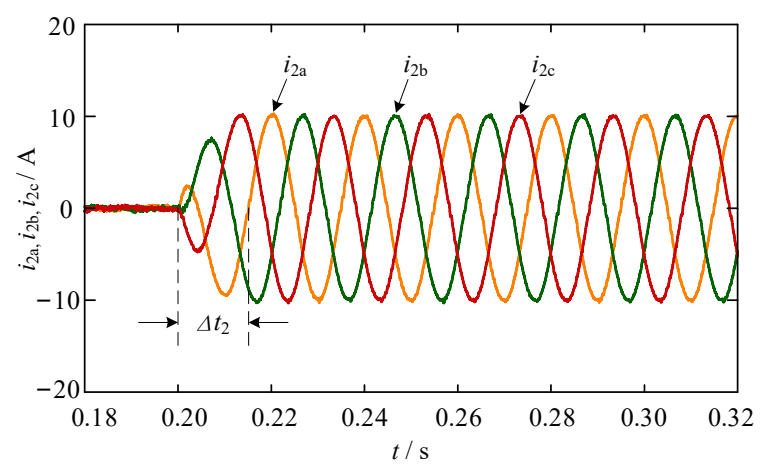

(b)

Figure 12. Simulation results comparison of the dynamic response performance: (a) Traditional method; (b) proposed method.

Figure 12a shows that the grid-connected current reaches the stable state after $\Delta t_{1}=55 \mathrm{~ms}$ with the traditional method, and Figure $12 \mathrm{~b}$ shows that the grid-connected current reaches the stable state after $\Delta t_{2}=15 \mathrm{~ms}$ with the proposed method. This indicates that the dynamic response performance is better than the former.

\section{Experiment Research}

To further verify the effectiveness of the proposed control strategy, an experimental platform of the three-phase LCL grid-connected inverter was built as shown in Figure 13. Figure 13a shows an actual picture of the prototype, and Figure 13b shows a connection diagram. In the experiment, the three-phase AC power was connected to the inverter through the autotransformer $\mathrm{T}_{1}$. The algorithm was implemented by the 32-bit floating point dual-core processor TMS320F28377D of TI Company, and the dead time of PWM pulse signal was set to $3 \mu \mathrm{s}$. A TEKTRONIX TPS2024 oscilloscope was used to observe the waveform, and a FLUKE 435 power quality analyzer was used to analyze the power quality of the 3-phase grid-connected current.

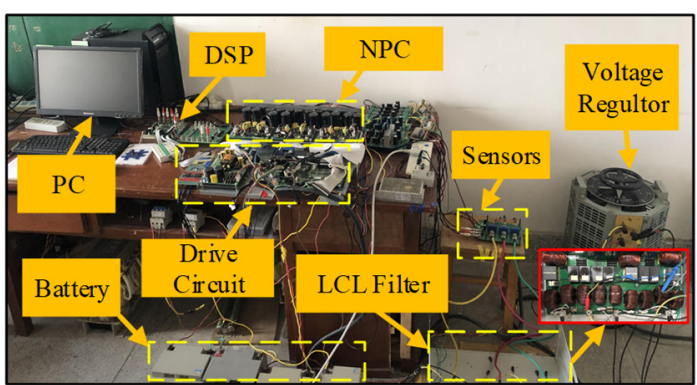

(a)

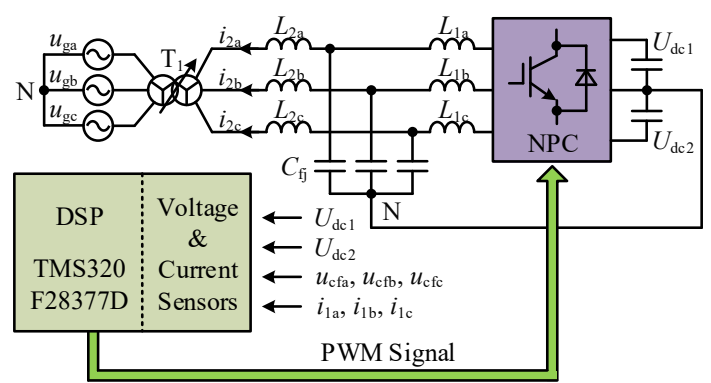

(b)

Figure 13. Three-phase LCL grid-connected inverter experimental setup: (a) Picture of the real products; (b) schematic diagram.

\subsection{The Steady-State Experiment}

Considering the possibility of serious LCL resonance, the experiment was carried out at a lower voltage level due to safety reasons, and the $G_{\mathrm{i}}(s)$ parameters and $K_{\mathrm{pi}}$ and $G(s)$ parameters $K_{\mathrm{pc}}$ were appropriately adjusted. Some experimental parameters are given in Table 2, and the remaining parameters were consistent with those shown in Table 2. 
Table 2. Some parameters of the experimental setup.

\begin{tabular}{ccc}
\hline Parameters & Symbol & Value \\
\hline Grid voltage & $u_{\mathrm{gline}}$ & $50 \mathrm{~V}$ \\
DC-side reference voltage & $U_{\mathrm{dc}}$ & $120 \mathrm{~V}$ \\
$G_{\mathrm{i}}(s)$ & $K_{\mathrm{pi}}, K_{\mathrm{ri}}$ & $7.5,400$ \\
$G(s)$ & $K_{\mathrm{pc}}, K_{\mathrm{rc}}$ & $0.7,200$ \\
\hline
\end{tabular}

According to Section 4.1, a reference current of 10 A was used. Figure 14 shows the steady-state experimental waveform results of the two methods, and Figures 15-17 show the FLUKE data comparison results of the two methods.

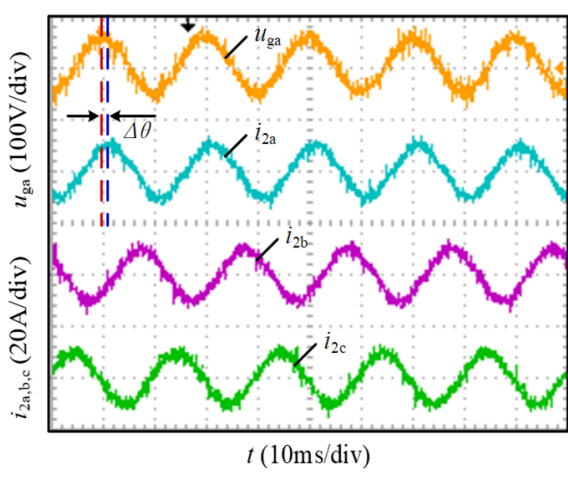

(a)

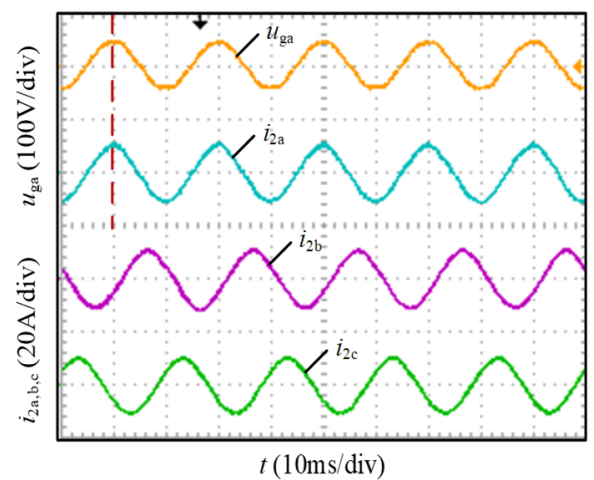

(b)

Figure 14. Steady-state experimental results: (a) Traditional scheme; (b) proposed scheme.

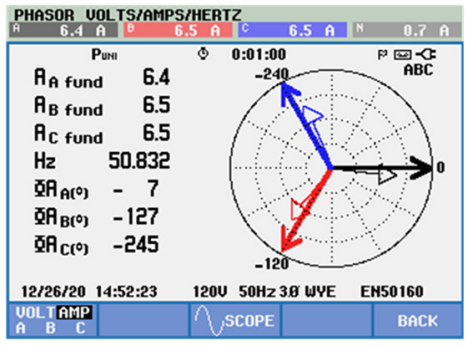

(a)

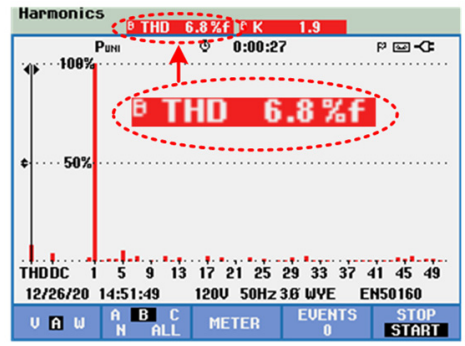

(c)

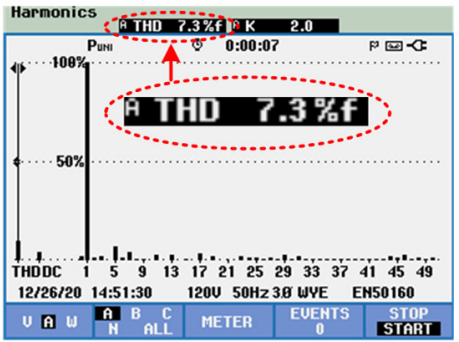

(b)

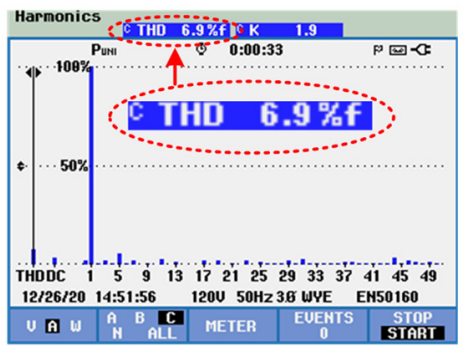

(d)

Figure 15. Power quality analysis results of conventional methods. (a) The measurement results; (b) THD of phase A grid-connected current; (c) THD of phase B grid-connected current; (d) THD of phase C grid-connected current. 


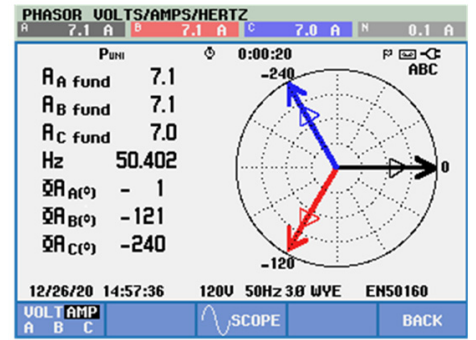

(a)

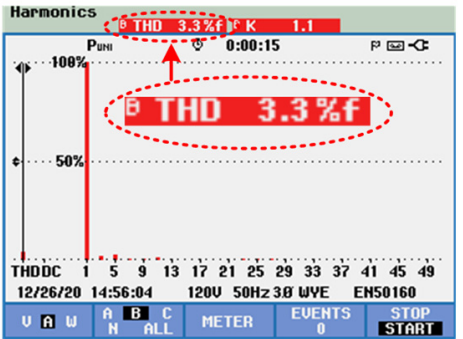

(c)

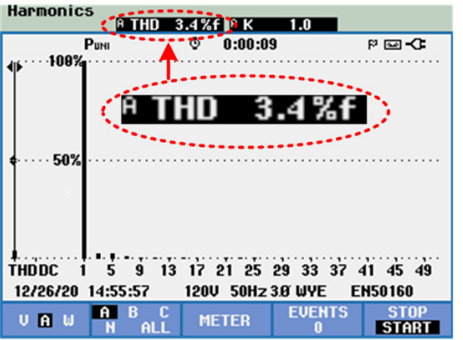

(b)

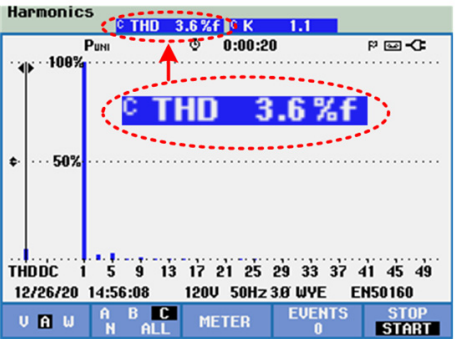

(d)

Figure 16. Power quality analysis results of the proposed methods. (a) The measurement results with; (b) THD of phase A grid-connected current; (c) THD of phase B grid-connected current; (d) THD of phase $\mathrm{C}$ grid-connected current.

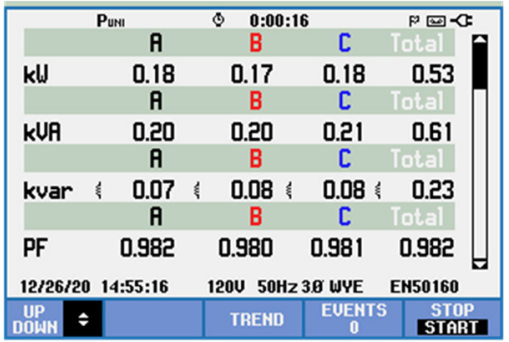

(a)

\begin{tabular}{|c|c|c|c|c|}
\hline \multicolumn{2}{|c|}{ Purn! } & $\begin{array}{l}0: 00: 0 \\
B\end{array}$ & C & $p$ \\
\hline kW & $\begin{array}{c}0.20 \\
\text { R }\end{array}$ & $\begin{array}{c}0.21 \\
B\end{array}$ & $\begin{array}{c}0.20 \\
ᄃ\end{array}$ & 0.61 \\
\hline kUA & $\begin{array}{c}0.20 \\
\text { A }\end{array}$ & $\begin{array}{c}0.20 \\
B\end{array}$ & $\underset{C}{0.21}$ & 0.61 \\
\hline kuar & $\begin{array}{c}0.01 \\
\text { A }\end{array}$ & $\begin{array}{c}0.01 \\
B\end{array}$ & $\underset{C}{0.00}$ & 0.02 \\
\hline $\begin{array}{l}\mathrm{PF} \\
12 / 26 / 2\end{array}$ & $\begin{array}{r}0.999 \\
14: 58: 15\end{array}$ & $\begin{array}{c}0.999 \\
120 \mathrm{~W} 50 \mathrm{~Hz}\end{array}$ & & $\begin{array}{c}0.999 \\
\text { EN50160 }\end{array}$ \\
\hline UPP/K & & TREND & $\begin{array}{c}\text { EUEHTS } \\
0\end{array}$ & $\begin{array}{l}\text { STOP } \\
\text { START }\end{array}$ \\
\hline
\end{tabular}

(b)

Figure 17. Analysis results of power and electric energy: (a) Traditional method; (b) proposed method.

It can be seen from Figures 14a and 15a that when the traditional indirect current control method is adopted, the effective value of the 3-phase grid-connected current is about 6.4 A (corresponding amplitude of $9.05 \mathrm{~A}$ ), and there is an obvious phase difference with the 3-phase grid voltage (about $7^{\circ}$ ). The corresponding power factor of Figure 17a is $\mathrm{PF}=0.982$. In addition, it can be seen from Figure 15 that the THD of the 3-phase grid-connected current is relatively high, which is $7.3 \%, 6.8 \%$, and $6.9 \%$, respectively. When using the method in this paper, it can be seen from Figure 16a that the effective value of the 3-phase grid-connected current is about 7.1 A (corresponding amplitude of 10.04 A), and it is almost in phase with the 3-phase grid voltage (about $1^{\circ}$ ), which corresponds to the power factor $\mathrm{PF}=0.999 \approx 1$ shown in Figure 17b. Moreover, it can be seen from Figure 16 that THD of the output of the 3-phase grid connection current is $3.4 \%, 3.3 \%$, and $3.6 \%$, respectively, which meets the requirement of the power quality standard IEEE519 of being below $5 \%$. The experimental results are consistent with the simulation results.

\subsection{Dynamic Experimental Results}

According to Section 4.2, Figure 18 shows the effect comparison of the dynamic response experiment of the grid-connected inverter under the power quality control condition. To minimize the current impact and ensure safe operation of the equipment, the method of voltage crossing zero detection was adopted in the algorithm, and the amplitude of the reactive current instruction $i_{\mathrm{q}}^{*}$ was triggered from 0 to $10 \mathrm{~A}$. 


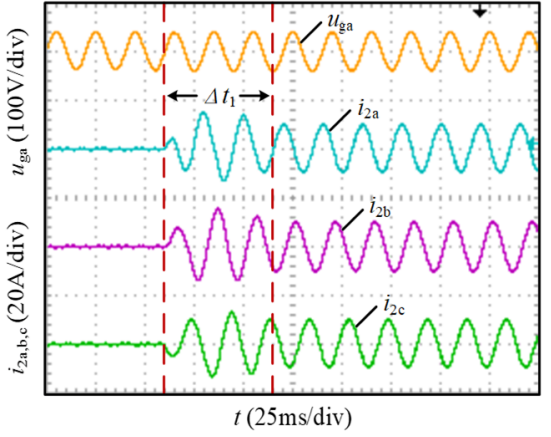

(a)

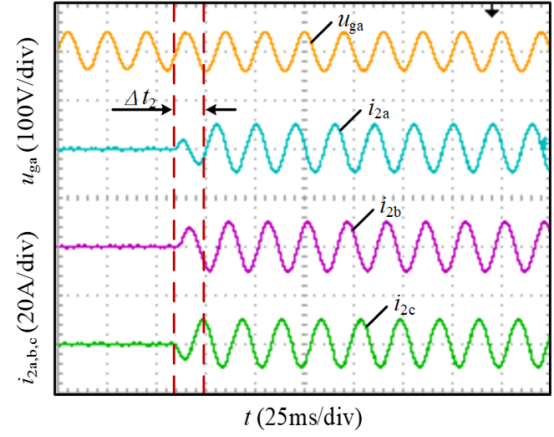

(b)

Figure 18. Experimental results of the dynamic response: (a) Traditional method; (b) proposed method.

According to the results of Figure 18b, the transient response time of the 3-phase gridconnected current in this paper is about $1 / 3$ of that of the traditional method as shown in Figure 18a, which quickly reaches the steady-state value of $10 \mathrm{~A}$. The results show that the dynamic response performance of the proposed method is better than that of the traditional method, and the experimental results agree with the simulation results.

\subsection{Comparison of the Experimental Results}

This section compares the experimental performance of the two methods, and the results are shown in Table 3.

Table 3. Comparison of the experimental performance.

\begin{tabular}{ccc}
\hline Parameters & Traditional Method & Proposed Method \\
\hline PLL & Yes & No \\
The THD of $i_{2 \mathrm{a}}$ (steady state) & $7.30 \%$ & $3.40 \%$ \\
The THD of $i_{2 \mathrm{~b}}$ (steady state) & $6.80 \%$ & $3.30 \%$ \\
The THD of $i_{2 \mathrm{c}}$ (steady state) & $6.90 \%$ & $3.60 \%$ \\
The PF of phase A (steady & 0.982 & 0.999 \\
state) & & \\
The PF of phase B (steady & 0.98 & 0.999 \\
state) & 0.981 & 1 \\
The PF of phase C (steady & & \\
state) & $6.4 \mathrm{~A}$ & $7.1 \mathrm{~A}$ \\
The effective value of $i_{2 \mathrm{a}}$ & $6.5 \mathrm{~A}$ & $7.1 \mathrm{~A}$ \\
The effective value of $i_{2 \mathrm{~b}}$ & $6.5 \mathrm{~A}$ & $1^{\circ}$ \\
The effective value of $i_{2 \mathrm{c}}$ & $7^{\circ}$ & $15 \mathrm{~ms}$ \\
The phase difference of phase & $55 \mathrm{~ms}$ & $0.02 \mathrm{kvar}$ \\
A & $0.23 \mathrm{kvar}$ & \\
Dynamic response time & &
\end{tabular}

It can be seen from Table 3 that the improved indirect current strategy does not need PLL, which simplifies the control system. In addition, the improved method shows a good performance in both the transient and steady state. During steady-state operation, the current THD of the improved method is much lower than that of the traditional indirect current control strategy, and effectively solves the defect of power factor reduction, so that the grid-connected inverter can operate at a unit power factor, and reduces the network loss. During transient operation, the improved method shows a shorter response time and better dynamic performance than the traditional methods.

\section{Conclusions}

In this study, an improved indirect current control method for an LCL grid-connected inverter was proposed. The error signal was calculated using the preliminary reference 
current and the reference value of the current loop was compensated for to achieve highprecision control of grid-connected current. The unit vector method was used to calculate the power grid phase, the phase-locked loop was omitted, and the traditional digital differential operator was improved to compensate for the calculation delay of a half beat. The closed-loop stability of the proposed method was analyzed by using the amplitudephase curve and pole diagram, and it was proved that the proposed method can maintain good robustness in a weak power grid. Compared with the traditional indirect current control strategy, the THD of the steady-state current is about $3.5 \%$, and the transient response time is about $1 / 3$ of that of the traditional method. Thus, it showed an excellent dynamic and steady performance.

Although the indirect current control strategy has better security, its tracking accuracy and stability are not as good as the direct current control strategy, so LCL grid-connected inverters rarely use the indirect current control strategy. Considering these problems, the main contributions of the indirect current strategy in this paper are as follows:

(1) The proposed preliminary reference current compensation strategy can realize unit power factor operation of grid-connected inverters, which effectively makes up for the defects of traditional methods to reduce the power factor.

(2) Compared with previous studies, the unit vector method was used to obtain the power grid phase information, which avoids the control system instability caused by improper phase-locked loop parameters.

(3) The relationship between system state variables was used to optimize the control structure, reduce the number of sensors, and reduce the system cost.

(4) The defects of the traditional differential operator were analyzed, improving the traditional differential operator by designing an FIR filter, and improving the experimental accuracy of digital control.

Author Contributions: Conceptualization, Z.L., L.Y., D.Y.; Investigation, D.Y.; Validation, Z.L. and L.Y.; Writing—original draft, Z.L. and L.Y.; Writing—review and editing, D.S., J.L., D.Y. and Z.P. All authors have read and agreed to the published version of the manuscript.

Funding: This research was funded by the National Natural Science Foundation of China, grant number 61861003. And The APC was funded by the National Natural Science Foundation of China, grant number 61861003.

Institutional Review Board Statement: Not applicable.

Informed Consent Statement: Not applicable.

Data Availability Statement: The data presented in this study are available on request from the corresponding author.

Acknowledgments: This study is supported by the National Natural Science Foundation of China (No. 61861003).

Conflicts of Interest: The authors declare no conflict of interest.

\section{References}

1. Blaabjerg, F.; Teodorescu, R.; Liserre, M.; Timbus, A.V. Overview of Control and Grid Synchronization for Distributed Power Generation Systems. IEEE Trans. Ind. Electron. 2006, 53, 1398-1409. [CrossRef]

2. Sanatkar-Chayjani, M.; Monfared, M. Stability Analysis and Robust Design of LCL with Multituned Traps Filter for GridConnected Converters. IEEE Trans. Ind. Electron. 2016, 63, 6823-6834. [CrossRef]

3. Liu, B.; Wei, Q.; Zou, C.; Duan, S. Stability Analysis of LCL-Type Grid-Connected Inverter Under Single-Loop Inverter-Side Current Control with Capacitor Voltage Feedforward. IEEE Trans. Ind. Inform. 2018, 14, 691-702. [CrossRef]

4. Rasekh, N.; Hosseinpour, M. LCL filter design and robust converter side current feedback control for grid-connected proton exchange membrane fuel cell system. Int. J. Hydrogen Energy 2020, 45, 13055-13067. [CrossRef]

5. Zhang, H.; Ruan, X.; Lin, Z.; Wu, L.; Ding, Y.; Guo, Y. Capacitor Voltage Full Feedback Scheme for LCL-Type Grid-Connected Inverter to Suppress Current Distortion Due to Grid Voltage Harmonics. IEEE Trans. Power Electron. 2020, 36, $2996-3006$. [CrossRef] 
6. Guzman, R.; de Vicuña, L.G.; Morales, J.; Castilla, M.; Miret, J. Model-Based Active Damping Control for Three-Phase Voltage Source Inverters with LCL Filter. IEEE Trans. Power Electron. 2017, 32, 5637-5650. [CrossRef]

7. Peña-Alzola, R.; Liserre, M.; Blaabjerg, F.; Sebastián, R.; Dannehl, J.; Fuchs, F.W. Analysis of the Passive Damping Losses in LCL-Filter-Based Grid Converters. IEEE Trans. Power Electron. 2013, 28, 2642-2646. [CrossRef]

8. Pan, D.; Ruan, X.; Bao, C.; Li, W.; Wang, X. Optimized Controller Design for LCL-Type Grid-Connected Inverter to Achieve High Robustness Against Grid-Impedance Variation. IEEE Trans. Ind. Electron. 2015, 62, 1537-1547. [CrossRef]

9. Pan, D.; Ruan, X.; Bao, C.; Li, W.; Wang, X. Capacitor-Current-Feedback Active Damping with Reduced Computation Delay for Improving Robustness of LCL-Type Grid-Connected Inverter. IEEE Trans. Power Electron. 2014, 29, 3414-3427. [CrossRef]

10. Yang, D.; Ruan, X.; Wu, H. A Real-Time Computation Method with Dual Sampling Mode to Improve the Current Control Performance of the LCL-Type Grid-Connected Inverter. IEEE Trans. Ind. Electron. 2015, 62, 4563-4572. [CrossRef]

11. Peña-Alzola, R.; Liserre, M.; Blaabjerg, F.; Sebastián, R.; Dannehl, J.; Fuchs, F.W. Systematic Design of the Lead-Lag Network Method for Active Damping in LCL-Filter Based Three Phase Converters. IEEE Trans. Ind. Inform. 2014, 10, 43-52. [CrossRef]

12. Peña-Alzola, R.; Liserre, M.; Blaabjerg, F.; Ordonez, M.; Kerekes, T. A Self-commissioning Notch Filter for Active Damping in a Three-Phase LCL -Filter-Based Grid-Tie Converter. IEEE Trans. Power Electron. 2014, 29, 6754-6761. [CrossRef]

13. Bahrani, B.; Vasiladiotis, M.; Rufer, A. High-Order Vector Control of Grid-Connected Voltage-Source Converters with LCL-Filters. IEEE Trans. Ind. Electron. 2014, 61, 2767-2775. [CrossRef]

14. He, N.; Xu, D.H.; Zhu, Y.; Zhang, J.; Shen, G.Q.; Zhang, Y.F.; Ma, J.; Liu, C.J. Weighted Average Current Control in a Three-Phase Grid Inverter with an LCL Filter. IEEE Trans. Power Electron. 2013, 28, 2785-2797. [CrossRef]

15. Shen, G.; Zhu, X.; Zhang, J.; Xu, D. A New Feedback Method for PR Current Control of LCL-Filter-Based Grid-Connected Inverter. IEEE Trans. Ind. Electron. 2010, 57, 2033-2041. [CrossRef]

16. Dick, C.P.; Richter, S.; Rosekeit, M.; Rolink, J.; De Doncker, R.W. Active damping of LCL resonance with minimum sensor effort by means of a digital infinite impulse response filter. In Proceedings of the 2007 European Conference on Power Electronics and Applications, Aalborg, Denmark, 2-5 September 2007; pp. 1-8.

17. Hanif, M.; Khadkikar, V.; Xiao, W.; Kirtley, J.L. Two Degrees of Freedom Active Damping Technique for LCL Filter-Based Grid Connected PV Systems. IEEE Trans. Ind. Electron. 2014, 61, 2795-2803. [CrossRef]

18. He, Y.; Wang, X.; Ruan, X.; Pan, D.; Qin, K. Hybrid Active Damping Combining Capacitor Current Feedback and Point of Common Coupling Voltage Feedforward for LCL-Type Grid-Connected Inverter. IEEE Trans. Power Electron. 2021, 36, $2373-2383$. [CrossRef]

19. Miao, Z.; Yao, W.; Lu, Z. Single-Cycle-Lag Compensator-Based Active Damping for Digitally Controlled LCL/LLCL-Type Grid-Connected Inverters. IEEE Trans. Ind. Electron. 2020, 67, 1980-1990. [CrossRef]

20. Xia, W.; Kang, J. Stability of LCL-filtered grid-connected inverters with capacitor current feedback active damping considering controller time delays. J. Mod. Power Syst. Clean Energy 2017, 5, 584-598. [CrossRef]

21. Wang, X.; Blaabjerg, F.; Loh, P.C. Grid-Current-Feedback Active Damping for LCL Resonance in Grid-Connected Voltage-Source Converters. IEEE Trans. Power Electron. 2016, 31, 213-223. [CrossRef]

22. Zou, Z.; Wang, Z.; Cheng, M. Modeling, Analysis, and Design of Multifunction Grid-Interfaced Inverters with Output LCL Filter IEEE Trans. Power Electron. 2014, 29, 3830-3839. [CrossRef]

23. Dannehl, J.; Fuchs, F.W.; Thøgersen, P.B. PI State Space Current Control of Grid-Connected PWM Converters with LCL Filters. IEEE Trans. Power Electron. 2010, 25, 2320-2330. [CrossRef]

24. Dannehl, J.; Wessels, C.; Fuchs, F.W. Limitations of Voltage-Oriented PI Current Control of Grid-Connected PWM Rectifiers with LCL Filters. IEEE Trans. Ind. Electron. 2009, 56, 380-388. [CrossRef]

25. Wang, J.; Yan, J.D.; Jiang, L.; Zou, J. Delay-Dependent Stability of Single-Loop Controlled Grid-Connected Inverters with LCL Filters. IEEE Trans. Power Electron. 2016, 31, 743-757. [CrossRef]

26. Zou, C.; Liu, B.; Duan, S.; Li, R. Influence of Delay on System Stability and Delay Optimization of Grid-Connected Inverters with LCL Filter. IEEE Trans. Ind. Inform. 2014, 10, 1775-1784. [CrossRef]

27. Huerta, F.; Pizarro, D.; Cobreces, S.; Rodriguez, F.J.; Giron, C.; Rodriguez, A. LQG Servo Controller for the Current Control of LCL Grid-Connected Voltage-Source Converters. IEEE Trans. Ind. Electron. 2012, 59, 4272-4284. [CrossRef]

28. Celick, D.; Meral, M.E. Current control based power management strategy for distributed power generation system. Control Eng. Pract. 2019, 82, 72-85. [CrossRef]

29. Xu, J.; Xie, S.; Zhang, B.; Qian, Q. Robust Grid Current Control with Impedance-Phase Shaping for LCL-Filtered Inverters in Weak and Distorted Grid. IEEE Trans. Power Electron. 2018, 33, 10240-10250. [CrossRef]

30. Wang, X.; Blaabjerg, F.; Loh, P.C. Virtual RC Damping of LCL-Filtered Voltage Source Converters with Extended Selective Harmonic Compensation. IEEE Trans. Power Electron. 2015, 30, 4726-4737. [CrossRef]

31. Jiao, Y.; Lee, F.C. LCL Filter Design and Inductor Current Ripple Analysis for a Three-Level NPC Grid Interface Converter. IEEE Trans. Power Electron. 2015, 30, 4659-4668. [CrossRef]

32. Yang, D.; Ruan, $\mathrm{X}$.; $\mathrm{Wu}, \mathrm{H}$. Impedance shaping of the grid-connected inverter with LCL filter to improve its adaptability to the weak grid condition. IEEE Trans. Power Electron. 2014, 29, 5795-5805. [CrossRef] 